\title{
Disrupting the heritage of place: practising counter archaeologies at Dumby, Scotland
}

Alex Hale, Alison Fisher, John Hutchinson, Stuart Jeffrey, Siân Jones, Mhairi Maxwell and John Stewart Watson.

\section{Contact details}

Dr Alex Hale, Historic Environment Scotland, John Sinclair House, 16 Bernard Terrace, Edinburgh, EH8 9NX T: 01316516769 E: alex.hale@hes.scot

Alison Fisher, Glasgow School of Art, Digital Design Studio, 67 Renfrew Street, Glasgow G3 6RQE: alisonfisher@hotmail.com

John Hutchinson, School of Geographical and Earth Sciences, East Quadrangle, University of Glasgow, Glasgow, G12 8QQ. E: j.hutchinson.1@research.gla.ac.uk

Dr Stuart Jeffrey, Glasgow School of Art, School of Simulation and Visualisation, 67 Renfrew Street, Glasgow G36RQ. E: s.jeffrey@gsa.ac.uk

Professor Sian Jones, Centre for Environment Heritage and Policy, University of Stirling, Stirling, FK9 4LA. E: sian.jones@stir.ac.uk

Dr Mhairi Maxwell, Glasgow School of Art, Digital Design Studio, 67 Renfrew Street, Glasgow G3 6RQ. E: M.Maxwell@gsa.ac.uk

John Stewart Watson, Stone Country Press Ltd. E: jsw1969@btinternet.com

Accepted for publication in World Archaeology published by Taylor and Francis. The final published version (including illustrations) is available at: https://

doi.org/10.1080/00438243.2017.1333923

\section{Abstract}

The notion of counter archaeology is echoed by the opposing faces of the volcanic plug of Dumbarton Rock, Scotland. On the one side is the 'official' heritage of Dumbarton Castle, with its upstanding $17^{\text {th }}$ century military remains and underlying occupation evidence dating back to at least the $8^{\text {th }}$ century AD. On the other side lies a landscape of climbing, bouldering and post-industrial abandonment. This paper develops counter archaeology through the climbing traditions and boulder problems at Dumbarton Rock and surfaces marginalised forms of heritage. Climbers and archaeologists have co-authored the paper as part of a collaborative project, which challenges the binary trope of researcher and researched and provides a model for a collaborative, co-designed and co-produced counter archaeology.

Key Words: Dumbarton Rock, climbing, 3D, collaboration, ACCORD, archaeology 


\section{Introduction}

This paper considers a counter archaeology project undertaken at Dumbarton Rock, Scotland, which focussed on climbing and bouldering, as a lens for observing co-designed, co-produced and participatory practices. It arises from the work of the ACCORD (Archaeology Community Coproduction of Research Data) project, which aimed to engage with communities of interest and practice, in order to investigate and record their heritage, through co-design and coproduction approaches (Jeffery et al 2015). It is co-written by regular Dumbarton Rock climbers and the archaeologists, from academia and the public sector, with whom they collaborated on the ACCORD project. We outline the context of the ACCORD project and specifically the work at Dumbarton Rock, known as 'Dumby' amongst the global rock climbing community. We also consider the processes of co-design and co-production and the effects they can have on project participants when working in a counter archaeology context. It also tackles some of the issues of marginalisation in archaeology. While Dumbarton Castle and the rock it stands on is a legally protected ancient monument, it is the archaeology of the rock itself and its sporting heritage that was addressed through the project (Figure 1). To close, we outline the rich and fruitful opportunities that counter archaeologies present when embedded in collaborative projects from the outset.

Whereas previous sporting heritage research has often taken an 'observational' approach (for example see Wood 2005), this paper proposes a participatory and collaborative counter archaeology at Dumby. In contrast to Wood (2016), who suggests that sporting heritage and history should be considered up until the $20^{\text {th }}$ century, we have chosen not to impose an arbitrary temporal cut off, viewing heritage as a form of contemporary practice and 'social action' (after Byrne 2008). The heritage of sport has been considered in overview and through specific examples in a recent edition of World Archaeology (Schofield 2012) and elsewhere (Hill et al. 2012). However, it can be argued that the voices, experiences and reflections of current sporting practitioners still remain unheard in much of this work. This paper directly addresses this absence. By adopting a collaborative approach, rather than the traditional process of academic writing, this account of climbing heritage is co-authored with climbers. It stands in contrast to authorised accounts of heritage of Dumbarton Castle, foregrounding aspects of its heritage that are usually marginalised or invisible, rendering them 'legible' in Byrne's use of the term (2014: 81-85).

Despite the rise of contemporary archaeology, climbing and bouldering has received little archaeological attention. One project that does focus on the archaeology of climbing is 'Vertical Archaeology'. Here the focus is on the material culture and 'hardware' of climbing, including a physical collection that ranges from some of the earliest climbing tools used to early guidebooks. The aim of the Vertical Archaeology project is to photographically document their collection and disseminate the images through their web portal (Vertical Archaeology 2016). Nevertheless, the project's focus on material culture follows a traditional heritage/museum format. In contrast, the collaborative approaches used in the ACCORD 
project sought to unsettle the authority of traditional recording techniques, by simultaneously recording both the rock climbing routes and the intangible values associated with them. Subsequently project data has also been made available for the climbers and others to access, for their own ends, rather than solely for the archaeologist's requirements.

The aim of the ACCORD project more generally, was to examine the opportunities and implications of digital visualisation technologies for community engagement and research through the co-design and co-production of 3D models of historic monuments and places (see Jeffrey et al 2015). The project team worked with 10 community groups to co-design and co-produce 3D records and models of heritage places, many of which the groups have ongoing relationships with. Importantly the capture of contemporary social values associated with heritage places through the use of focus groups was an integral part of the ACCORD methodology. Furthermore, a statement of social value was archived with the resulting digital records and 3D objects and embedded in the associated contextual metadata. Dumbarton Rock was the focus of one of the 10 ACCORD community partners, the climbers making up a 'community of interest and practice', rather than a formally constituted group. Most are regular climbers at Dumby and as such their chosen heritage is distinctly counter archaeological, focusing as it does on the climbing routes and bouldering problems associated with the cliffs around Dumbarton Rock, rather than the Castle sitting on the rock itself. In essence, it is a form of ongoing 'living heritage', which contrasts with the representation of the historic elements as things of the past, separate from the present.

This paper deviates from normal academic practice in that it involves archaeologists and climbers in a process of both co-production and co-authoring. The climbers amongst us were lead authors on the section focusing on climbing heritage, and their reflections on the ACCORD project feature prominently in the final section. The archaeology and heritage practitioners amongst us led on other sections. Nevertheless, the paper was created together and builds on our shared overall experience of the project, including the other climbers who participated in the ACCORD project. We see counter archaeology as a body of practices that challenge conventional archaeological recording and landscape survey, with their focus on physical data gathering (survey, excavation, etc.), analysis and hypothesis testing. Instead, it integrates these recording practices with contemporary social concerns revealing marginalised forms of heritage (Buchli and Lucas 2001: 14), thereby breaking down the separation of past and present produced through traditional archaeological practice. The collaborative 3D digital technologies used in the ACCORD project in conjunction with a focus on social values can be seen as a form of 'counter-mapping', as developed by Byrne (2008, 2014; Byrne and Nugent 2004) and Harrison (2011). This 'involves recording alternate, 'hidden' or non-mainstream social geographies', thus giving voice to marginal understandings of the past and present (Harrison 2011: 79). In the case of this research, the practice of counter-(archaeology) mapping sheds light on a form of counter heritage, which, as described 
below, is explored, encountered, practiced, and perhaps most importantly shared, through the act of climbing, bouldering and spending time with climbers at climbing venues.

\section{The multiple heritages of Dumbarton Rock}

Dumbarton Rock lies on the north shore of the Firth of Clyde. The Rock is a volcanic plug that stands proud from the surrounding flats of the Clyde foreshore. This prominent place draws the eye from miles around and has attracted visitors for thousands of years. Its dominant position in the landscape is attested to by its use as the capital of the Kingdom of Strathclyde from the $8^{\text {th }}$ century AD. Subsequently, it has remained a politically and tactically important place, becoming a major military installation that continued in use right up until the First World War (Canmore Record, ID 43376, Historic Environment Scotland 2016 i). Many of the military buildings and fortifications dating to the $17^{\text {th }}$ and $18^{\text {th }}$ centuries still remain and a number of archaeological investigations have uncovered earlier medieval structural remains and artefacts, along with some Roman pottery (ibid.). These upstanding structures and archaeological remains lie at the centre of the 'authorised heritage discourses' (Smith 2006) surrounding the Rock, realised through practices of designation, conservation, presentation and consumption by visitors. Many of the buildings are designated Listed Buildings and the entire Rock is a designated Scheduled Monument, including the rock faces and boulders that are used for climbing. It has an important place in the production of national heritage, which is reinforced by the fact that it has been taken into the care of Historic Environment Scotland (HES), the Non-Departmental Public Body established to investigate, care for and promote Scotland's historic environment. The site is open to the public and heritage interpretation focuses on the medieval history of the Rock, the post-medieval military fortifications and the Governor's House, which is regarded as a fine example of Georgian architecture. The car park and entrance is on the south side of the Rock and large numbers of tourists explore the structures located on the south face, some of them making it up White Tower Crag to take in the stunning views. Nevertheless, the cliffs and boulders on the north and north-west faces of the Rock, which are the focus of the climbers' attentions, remain out of sight, an alternative arena of heritage practice.

In 2012, alternative heritages at the rock began to surface when Historic Scotland was encouraged by a local Councillor to consider cleaning graffiti that had accumulated on the boulders and at the foot of the crag, on the north side of the rock (Williams 2012). The graffiti ranged from $19^{\text {th }}$ century carvings to more recent painted slogans, names of specific climbing routes and very recent graffiti tags and blow-ups. Aside from some preliminary work, the cleaning of the graffiti took place in consultation with the climbers, after they expressed concern about the loss of some of the graffiti and potential damage to the climbing routes caused by the cleaning process. Certain pieces of graffiti that were identified by the climbers as being explicitly part of their (climbing) heritage were not removed in the cleaning programme. For example, a shield-shaped outcrop known as the 'Shield' is part of a 'problem' (or recognised sequence of climbing moves) and has 'Robert de Bruce' painted over the 
protruding part. Another piece of graffiti that was left in situ was a political poem painted by a climber with the nickname 'Bam Bam' during the 1979 Scottish referendum vote. He took a quote from a speech by John Macpherson, a crofter from Skye in the 1880s, who was a prominent figure of the Glendale martyrs (Hunter 2011) (Figure 2):

\author{
IT WOULD \\ BE AS EASY TO STOP \\ THE ATLANTIC OCEAN AS TO \\ STOP THE PRESENT AGITATION \\ UNTIL JUSTICE HAS BEEN \\ DONE TO THE PEOPLE. \\ BAM BAM
}

This deliberate maintenance of some of the graffiti at Dumbarton Rock indicates one of the developing approaches that HES is beginning to take with graffiti art. This example suggests a broader organisational shift, which is beginning to enable the recognition of broader, more nuanced, complex and unsettling forms of heritage (Hale \& Anderson forthcoming). Graffiti is increasingly recognised as an important cultural practice and form of heritage worthy of investigation (Frederick 2009) and in some instances protection (Forster et al 2012, Merrill 2015). It also shows a growing recognition of social value as an integral aspect of the significance of heritage places (see Jones 2016). As we discuss below, the ACCORD project's focus on social value also facilitated the unofficial heritage at Dumbarton Rock to be included in the National Record for the Historic Environment and HES's Revised Statement of Cultural Significance for Dumbarton Rock (Historic Environment Scotland 2016(i) and 2016(ii) and 2016).

\title{
ACCORD and counter archaeology at Dumby
}

Co-production of heritage records with communities has begun to be accepted as mainstream heritage practice over recent years. For example, Archaeology Scotland's Adopta-Monument scheme, which at the time of writing has just celebrated its 25th anniversary (Archaeology Scotland 2016), trains volunteers in order to give them the skills to record, protect and promote their local heritage. Indeed, there are some examples of projects that use 3D digital technologies, in community-led recording of rock art and physical structures (e.g. Bryan and Chandler 2008; McCarthy 2014). However, for the most part the emphasis in these projects and schemes remains firmly focused on training and the creation of a record of physical heritage assets. Furthermore, despite the well-known pragmatic benefits in empowering communities to protect and promote their heritage (Smith and Waterton 2009), the transformation in terms of people's social and personal attachments to these places through taking part in co-production or co-design is often overlooked or not captured (Jones 2016). In contrast, the ACCORD project was not focused on the provision of training nor with 
capacity building. In recruiting participants, ACCORD generally worked with community groups who had pre-existing relationships with our project partners at Archaeology Scotland and the Royal Commission on the Ancient and Historical Monuments of Scotland (RCAHMS, known as Historic Environment Scotland, since 2015). However, the research questions at the heart of ACCORD focused on the contemporary social values that the community groups they worked with associated with heritage places (Jeffrey 2015). At the same time, the ACCORD project team explored the impact of the co-production of 3D digital visualisations on community relationships with heritage places. The project thus sought to reflect on the forms of significance, authenticity and value acquired by the 3D digital objects themselves through the co-production process (see Jones et al forthcoming).

Through the use of ethnographic methods, such as focused group interviews and participant observation, the project sought to document people's relationships to the heritage throughout the recording process. We were careful to not let dominant heritage discourses direct us, but rather to be deliberately open and exploratory in both discussion and site selection. With each community group there was an initial focus group in which we explored what heritage sites were of significance to them and why. Community participants, researchers and heritage professionals then selected the monuments and sites that would be recorded and subsequently participated in the data capture, processing, and archiving (Figure 3). In the main we used consumer level equipment and open or free software and the relatively easy to learn, but very powerful techniques, of photogrammetry (also known as Structure from Motion/ SfM) and Reflectance Transformation Imaging (RTI). The opportunities that these technologies offer for wider participation in recording heritage have been noted by others (Bonnachi et al 2014, McCarthy 2014, Miles et al 2015, Reilly and Beale 2015). Laser scanning was on occasion offered, but was not preferred as it is both an expensive and unavoidably specialist technique. All groups were fully engaged with the data capture, processing and management of the 3D data, including in some instances the use of 3D printing of models generated from the data capture. This was a deliberate departure from the approach of many collaborative projects, which undertake data capture and recording processes with community partners, but then carries out the data-processing and dissemination as a separate phase, reasserting the role of the expert.

Following data-capture and processing, comprising multiple site visits, we then held a focus group to review peoples' experience of taking part in the recording process and how they ultimately valued the results. A summary statement of significance with a primary focus on the contemporary community context and social value was drafted based on the focus group and then circulated to all participants for re-drafting, input and clarification. These coproduced summary statements are published alongside the 3D record outputs produced for all ACCORD projects. The ACCORD archive is published online at the Archaeology Data Service website under a Creative Commons attribution license for free re-use. The role of community co-production of 3D records and models in the production and negotiation of authenticity is 
discussed in Jones et al (forthcoming), while the, perhaps unexpected, creative power of these technologies for communication and engagement is discussed by Maxwell (forthcoming).

Our methodology at Dumbarton Rock was adapted specifically in relationship to the place and to the nature of the group. ACCORD project Co-Investigator Alex Hale had been in longstanding communication with the climbers here due to concerns over the effect of cleaning graffiti from the climbing routes (discussed above). Seven climbers took part in this project, recruited via two climbers who acted as conduits to the wider climbing community around Dumby (and who are co-authors of this paper). The group can be characterised as an informal community of shared interest and practice, all of whom are passionate about the climbing and Dumby's climbing history, but also the post-industrial environment of Dumbarton Rock. The group included active and accomplished climbers, one of whom was a postgraduate student conducting research on the environment and recent history of climbing at Dumbarton Rock, another who is a climbing guide publisher and a third who is the dumby.info website designer. Aside from these 3 individuals, the other climbers had varying degrees of familiarity with the 'Dumby scene', but all, with one exception, had climbed on the iconic routes on the north-west sector of Dumbarton Rock. All the climbers who participated were men ranging in age from their 20 s to their 60 s. They had equally varied climbing experience, ranging from less than a year since starting to almost 50 years' experience.

We carried out the recording over four afternoon/evening sessions spread out over the duration of a week. Photogrammetry was used for the boulders and lower rock faces, RTI for the incised graffiti and time of flight laser scanning for the main rock face, which was inaccessible for photogrammetric recording. There was a coming and going of individuals and not everybody attended all sessions. We held the focus groups in the restored dining room of Dumbarton Castle, by kind permission of HES, which although a practical location, also enabled all partners to recognise that ACCORD was an opportunity to surface an alternative perspective of what was important to them at a place that previously has been prescribed through authorised heritage discourses. The tangible substance of the place was key to this and on some occasions it was easier to continue discussions at the rock face itself, and to even process the results there on our laptops (Figure 4).

As a result of the work at Dumby, the group decided to co-design and co-write this paper. This process involved all partners gathering together for a preliminary discussion and as a result of which the overall plan of the paper was created (as a mind-map). This formed the basis from which sub-groups of writers self-identified and offered to write individual sections. Subsequently, the lead author collated the sections and put it into a single document, which was passed around all authors and each subsequent adaptation was seen and agreed by all the contributors. As such, this approach builds on the cumulative heritage of Dumby, by creating a co-produced, accessible journal paper. 


\section{Climbing heritage at Dumby}

Climbing heritage is a complex mix of the tangible and intangible and with its own language and shorthand. It includes the intangible aspects of the environment, such as the oral traditions about previous climbers and route-makers, which the climbing community value strongly. However, it centres on the tangible boulders and rock outcrops that provide both actual and metaphorical grittiness, in the case of Dumby, its urban character and the physicality of climbing, which were difficult to express, away from the rock and when confined in the four walls of the castle dining room. Although the ACCORD Dumby group were interested in a counter archaeology of the rock focusing on their experiences and the climbing heritage, there was also a desire for formal recognition of its significance by official heritage bodies, such as HES. The group were therefore motivated to create a particular kind of record of the site, which they hoped would "legitimise" or "make official" its heritage. As one of the climbers put it "we need to stamp our rights to the place". In this case, ACCORD offered an opportunity to explore new methods for promoting the sporting heritage of this site, while for the researchers this project was a great opportunity to examine the transformative power of these technologies to see whether they changed or enhanced already pre-existing strong attachments to place.

Climbing has its own conventions for representing topography, specifically the character and difficulty of climbing routes and their main features. Routes are graded according to their degree of technical difficulty. An alpha-numeric classification system defines both the overall difficulty of a route, followed by the technical difficulty of the hardest part of the route, for example E means 'Extreme' and the higher the following number, the more 'extreme' the route is considered (Grimes 2016). Dumby is known internationally for the routes up the main crag and for its boulder problems. Rhapsody (E11 7a) on the main crag was first ascended by Dave MacLeod in 2006 (Ryan 2006). It is still considered one of the hardest traditional climbing routes in Scotland, and the first route in Britain with such a high level of difficulty (E11). Equally the many large boulders beneath the main climbing face hold multiple well known 'boulder problems' (shorter climbing routes with fewer moves). The nature of the rock at Dumby and its long history of development as a climbing site mean that many of these problems are renowned for their technical complexity and difficulty.

As with other kinds of heritage, however, the significance of climbing at Dumby extends far beyond the conventions of topographic description and grading within the sport. Under the ramparts of Dumbarton Castle, since as early as the 1960s, a climbing culture has been nurtured by the hard basalt of the rock's imposing north-west face and its geological offspring of boulders. Like clandestine invaders of old, this climbing community has quietly mustered on the spatial margins of the castle's official heritage fabric, going largely unseen by those tasked with its care; the liminal, 'edgeland' (Farley \& Roberts 2011) nature of the rock's north west area providing the latent space for a 'ground-up', organic counter heritage to emerge. This is a form of heritage that is strongly grounded in practice and performance, the action of 
bouldering and climbing at Dumbarton Rock bringing into focus the associated history of aggregated practice over the past 50 years or so.

In contrast to the apparently more static heritage fabric atop the rock, it is a lively and dynamic heritage, drawn from a collective culture of embodied movement and tactile engagement with landscape. This "more-than representational" (Lorimer 2005) culture of embodiment finds conceptual expression in landscape phenomenology; an approach that foregrounds "the simultaneous and ongoing shaping of self, body and landscape via practice and performance...in which, self, landscape and indeed culture itself inhere, circulate and emerge" (Wylie 2007, 166).

Due to its proximity and witness to the post-war decline of Clydeside industries, a postindustrial, 'wasteland' aesthetic is bound up in Dumby's climbing identity. Broken glass, discarded beer cans and defiant scrawls of graffiti lend the place a unique sense of grit amongst grandeur. It is a place of edges and edginess - a serious place to climb and sometimes a hard place to be - but one which greatly rewards those who can 'stick it out' with a heady and intoxicating experience of landscape, alongside climbing initiation and apprenticeship. As the Scottish Mountaineering Club Lowland Outcrops guide says of Dumby "for as many that love the seriousness and technicality of the many boulder problems, there are lots of climbers whose blood runs cold at their mere mention. Dumbarton isn't a crag for the weak-fingered or the weak-hearted, but perseverance will strengthen both" (SMT 1994: 25)

Indeed, the notion of "perseverance" lies at the heart of Dumby's climbing philosophy. The almost monastic dedication required to unlock its hardest climbs demands a ritual of repeated visits; of extended time spent refining sequences, climbing, failing, resting, and contemplating. Through this act of "dwelling" the "temporality of the landscape" (Ingold 2000) comes to the fore, whereby the shifting tides, the idling of birds, the ever changing skies and the light it casts upon the rock become so bound up in the kinaesthetic rhythms of climbing, that landscape and climber become mutually entangled. As Ingold states, it is through the practical activities (or "taskscapes") of "dwelling" that "the landscape becomes a part of us, just as we are a part of it" (2000: 191). Despite Dumby's hard-edged reputation then, it is a place that softens with acquaintance, with regulars drawn back for its natural amenity and sense of place, as much for its climbing challenges.

As the training ground for hard Scottish rock-climbing, the rich stratigraphy of Dumbarton Rock's climbing heritage is delineated through the narrative of the 'first ascent': generational markers that refuse to fade due to their continual retelling and re-enactment- a kind of 'invisible archaeology' that although imperceptible to the casual observer, marks the rock as profoundly as the graffiti which perpetually adorns its surface. Like the dates of famous battles, cutting-edge first ascents such as Cuthbertson's Requiem (E8 6c) in 1983, Smith's Pongo (8a) in 1999 and MacLeod's Rhapsody (E11 7a) in 2006, resonate loudly in the storied 
timeline of 'Dumby's' sporting heritage. The embodied engagement with the heritage of the rock forms a kind of active, counter heritage (Figure 5).

The guidebook acts as the cultural repository in which the name, grade and creator of the first ascent is recorded. This quantification of Dumby's landscape into named problems and routes provides the bedrock of shared cultural meaning from which its climbing community refers and operates. In addition to guidebooks, oral history, the (re)telling of stories and the day to day discussion of 'beta' provides a vital means of transmission between one climbing generation and the next. 'Beta' is a climbing term that refers to the sharing of information about a climb in respect of its technical difficulty. The 'beta' at Dumby is knowledge earned by the climber who has toiled hard to understand, achieve and complete the problem they have been posed by the boulders. In this respect the 'beta' from any climbing route is an equivalent oral history, which provides hidden knowledge to the attuned ear of the listener. To the Dumbarton climber, 'Dumby' exists not as a homogenous sprawl of basalt (see figure 1), but as a series of lines, grades, names, people, stories and events; all of which are underpinned by an ongoing, kinaesthetic engagement with its landscape through "dwelling" (Ingold 2000).

This might appear to render 3D digital recording and modelling a rather strange, even alien, mode of engagement from the climbing perspective. However, the Dumby climbing community has a significant online presence, regularly employ digital techniques, particularly photography, to illustrate Dumby, and to share and promote their activity. The group included a number of talented photographers, graphic designers, writers, cinematographers and web designers. Their work can be viewed on a website dedicated to the venue (Dumby 2016), as well as YouTube, Facebook, Vimeo, and dedicated climbing forums. The production and consumption of visual representations thus constitutes a more detached mode of engagement with Dumby that was already a significant component of community practice, and 3D digital modelling was seen as a natural extension of this practice by the climbers involved in ACCORD.

Web technology allows for the collective display of their chosen media and provides an insight into the community around the rock climbing site. As a result of this online engagement, the climbing community are exposed to and use digital technology on a day to day basis. They use this to share their heritage, knowledge and for self-promotion. We must also remember that climbers are part of a larger global culture that is geographically dispersed, rather than concentrated in one place. In this respect the ACCORD project at Dumby reflects an opportunity between two distinctly different communities to share practice. This is reflected by one of the climbing partners,

'This collaboration validated what the climbers saw as a legitimate but often suppressed heritage - perhaps the curation of it digitally helped bring it to wider attention within academic and archaeology worlds, even if the technology wasn't seen itself as the missing link in the heritage story - the missing link was more one of amplification of voice.' 
Dumby's place in Scottish climbing heritage draws visitors from around the world. The internet, technology and film facilitates communication within the group and the sharing of stories, part of a long-established tradition of story-telling as illustrated by Robin Lloyd-Jones,

'The tales brought back by student club representatives attending Scottish Mountaineering Club (SMC) dinners were eagerly awaited. The tales of our (still living) Victorian mountaineering heritage were as remarkable to us as those scientists who discovered the living fossil coelacanth brought up from far down in the Indian Ocean' (Lloyd-Jones 2013, 136).

\section{ACCORD at Dumby: practice and potentials}

What then is the place of the ACCORD project in this long-established tradition of storytelling? How do the co-production practices involved provide new and potentially transformative ways of relating to boulders and rock faces of 'Dumby'? And how do the resulting models create new forms of detachment and engagement with place? In this section we explore these questions through the reflections of the ACCORD participants at Dumby and highlight what potential opportunities arise from this kind of collaborative, counter-archaeological practice.

It was with the Dumby group that issues around counter archaeology were most apparent in the ACCORD project. The digital techniques used in the ACCORD project can be learned and quickly deployed by non-experts, but in heritage contexts they have largely been deployed by heritage professionals, framed by expert priorities as opposed to community significance. Because of the specific research objectives of the ACCORD project, and the use of co-design and co-production, this is an early instance of heritage bodies (academic/professional) working with communities in a way that encourages the groups themselves to identify what is meant by heritage, and how it is significant to them. As one of the climbers explained in frustration at the marginalisation of climbing in authorised heritage discourses at Dumby:

I have been going on for years about Dumbarton Rock being one of our finest examples of modern 'sporting heritage', a kind of living history and an example of community 'ownership'.

The collaborative 3D recording and visualisation of the boulders and rock faces, in conjunction with intangible values, during the ACCORD project, rendered this living climbing heritage visible in opposition to authorised heritage discourses. Indeed it resulted in the redrafting of the HES 'Statement of Significance' for Dumbarton Castle, to include a section on the social value of the climbing heritage at the rock, co-authored by the climbers and the ACCORD team (HES 2015). This new section highlights the intimidating reputation and a mystique surrounding Dumby as a climbing site, but also points out that its significance is rooted in its unique character and atmosphere. It is seen as having a gritty character linked to the industrial heritage of Dumbarton, particularly as this recent (but now largely disappeared) 
industrial infrastructure provided the striking photographic backdrop to many iconic images of significant 'first ascents' in the 1980s. The hard graft of industry offers an analogy for climbing which also 'requires a graft and an industry'. The graffiti that marks the rocks and the detritus left by local revellers add to this grittiness. At the same time, Dumby is seen as a captivating place of raw beauty informed by the changing weather and tides.

The ACCORD project was also seen by the climbers as a political act of validation, the 3D scanning for example cementing the 'monument' status of the actual geology to the climbers' perception of place (rather than the digital archive itself being the end product).

Nevertheless, it was ultimately not the digital products themselves, but the practice of producing them, and the attention to this form of heritage that they engendered, which emerged as the most significant outcome (and see Jeffrey 2015). This is clearly articulated by one of the climbing partners:

'Through ACCORD, I discovered new layers of understanding of a landscape I had perhaps under-appreciated and it made us think on the complex sporting heritage link with history, landscape and performance (in this instance the bouldering). What of the 'future direction' of guide-books on climbing after the experience with ACCORD? Overall, the experience had reinforced the idea that guidebooks should perhaps be more inclusive of landscape and history, and show a greater creativity towards representing elements which may inform more of the climbing experience than has traditionally been accepted i.e. the ambience and heritage around Dumby in all its phenomenological variety. This could be represented in more creative photography (a 'wider lens'), route-naming, and historical notes. The 3D element to the process was fascinating but the actual tools to make use of this material e.g. '3D guidebooks' is still some way off in terms of practical access and manipulation by traditional publishers. It will perhaps be more accessible to the new breed of online guidebook developers, where this sort of material, if it could be notated, would be immensely useful.'

That is not to suggest that deficiencies and shortcomings went unrecognised. Perhaps unsurprisingly, given the tactile nature of climbing, while there was enthusiasm for the photo-realism of photogrammetric models, 3D prints were considered 'plastic- $y$ ' and too vivid in colour to be appealing records. Yet at the same time the future potential of physical records created from the digital outputs was explored. As one climber put it:

'The creation of a miniature 3D print of the Eagle Boulder was a novel example of how such technology can capture the material forms of our climbing heritage. One might fancifully imagine a time when such prints may be up-scaled to reproduce full-size artificial boulders, such as those recently installed at the Cuningar Loop Forest Park in sculpted concrete' (Climb Scotland 2016). 
One of the climbers articulated two particular outputs from the project when they mentioned how the 3D data could provide opportunities for themselves and heritage organisations, by suggesting that:

'The 3D print also appeals to the 3D imagination of the climber, more so than a $2 \mathrm{D}$ photographic image, and there was a real sense of intrigue and playfulness at being able to hold a mini Eagle Boulder in the palm of your hand. We even joked that such prints could be sold in the Castle's gift shop as a souvenir for visiting climbers!'

This reflection of multiple opportunities, presented by the 3D data for both climbers and heritage organisations, illustrates how positions of the partners had developed during the course of the project. With these future visions in mind, an important element of the ACCORD project relates to how the final digital outputs were to be managed and preserved. Actively preserving material in an archive, especially digital content, is not a trivial exercise (nor without financial cost), but it makes an important statement about the value of the material being deposited, and by extension reinforces the value of the site to which that material relates (Jeffrey et al. 2015, 290). So the fact that the final RTI's, photogrammetric models and raw laser scan data generated from graffiti, climbing routes and boulders were carefully documented and deposited with a trusted digital repository (in this case the Archaeology Data Service, with a copy going to the HES archive) is a statement of the significance of the site in itself. Similarly, the updated description in the publically accessible national monuments record for Dumbarton Rock, which now explicitly notes its graffiti and climbing heritage, creates new forms of significance for the site (HES 2016(ii)).

\section{Reflections}

The practice of counter archaeology at Dumby has had impacts that are both unforeseen and welcome. At Dumby, as with all the ACCORD projects, a complex series of relationships unfolded, both during the recording process and in the period of reflection that followed. Of all the ACCORD projects, Dumby, was perhaps the most politically aware from the outset. The climbers' pre-existing engagement and their participation in contributing to the decisionmaking over the graffiti cleaning and the underlying feeling that the sporting heritage of the site was being over shadowed (or completely ignored) in favour of the authorised heritage discourse around the castle, were evident from the outset. As a result of this the group's enthusiasm for participating in the project, and their choice of recording targets, can be seen as an act of counter archaeology.

Collaborative 3D recording and modelling as a form of counter archaeology has resulted in a shift from authorised heritage to marginalised heritage at Dumby. It has also challenged the prioritisation of product over process. It reveals that it is not just the resulting records, but importantly also the act of recording as a form of co-production, which allows marginalised forms of heritage to be fore grounded and negotiated. The climbing community have always 
valued their physical and performative engagement with the site, understanding and experiencing its heritage through the process of finding, following or creating routes up the rock. The process of digital recording offered yet another mode of engagement with the heritage of the site. In this case, it was a process that ultimately led to a broader recognition within the heritage domain of the site's climbing history and a validation of its importance. Within the context of significance and impact of the project, we should also reflect on how this form of counter archaeology can affect participants and inform future opportunities. In particular archiving digital records and models alongside a record of the intangible social values associated with Dumby is important in terms of aspirations for future uses of this material and even potential spin off opportunities. These are likely to emerge as climbing guides integrate both new technology and new perspectives on the broader physical and historical landscapes in which the climbers operate.

\section{Acknowledgements}

Thanks to all the ACCORD project partners. Thanks to Historic Environment Scotland for providing the Governor's House at Dumbarton Castle and for access to the Statement of Significance for Dumbarton Castle. The authors would also like to thank the two anonymous reviewers for their comments on an earlier draft of this paper. This work was supported by the Arts and Humanities Research Council under Grant AH/L007533/1.

\section{References}

Archaeology Scotland (2016) http://www.archaeologyscotland.org.uk/our-projects/adoptmonument (date accessed: 303/11/17).

Bonacchi, C., Bevan, A., Pett, D., Keinan-Schoobaert, A., Sparks, R. Wexler, J. and Wilkin, N. (2014). Crowd-sourced Archaeological Research: The MicroPasts Project. Archaeology International 17, pp.61-68. DOI: http://doi.org/10.5334/ai.1705

Bryan, Paul G., and Chandler, Jim H. 2008. "Cost-Effective Rock-Art Recording within a NonSpecialist Environment." The International Archives of the Photogrammetry, Remote Sensing and Spatial Information Sciences 37(B5) pp. 259-264.

Byrne, D. (2008). Heritage as social action. In G. Fairclough, R. Harrison, John H. Jameson Jnr. and J. Schofield (eds) The Heritage Reader, pp. 149-74. Routledge, London.

Byrne, D. (2014). Counter-mapping and migrancy on the Georges River. In J. Schofield (ed.) Who Needs Experts? Counter-mapping Cultural Heritage, pp. 77-93. Farnham: Ashgate.

Byrne, D. and Nugent M. (2004). Mapping Attachment: a spatial approach to Aboriginal postcontact heritage. Sydney: Department of Environment and Conservation, New South Wales.

Buchli, V. and Lucas, G. (2001) Archaeologies of the Contemporary Past, Routledge: London. Climb Scotland (2016) http://www.climbscotland.net/where-to-go/get-outdoors/cuningarloop-boulders (date accessed: 04/11/16) 
Dumby.info (2016) http://www.dumby.info, (date accessed: 13/11/16).

Farley, P. and Roberts, M. (2011) Edgelands: Journey's into England's True Wilderness, Jonathan Cape: London

Forster, A., Vettese-Forster, S. and Borland, J. (2012) Evaluating the cultural significance of historic graffiti, in Structural Survey, 30:1, 43-64.

Frederick, U. (2009) Revolution is the New Black: Graffiti/Art and Mark-making Practices. Archaeologies: Journal of the World Archaeological Congress (2009) DOI 10.1007/s11759009-9107-y.

Grimes, N. (2016) A brief explanation of UK traditional climbing grades, https://www.thebmc.co.uk/a-brief-explanation-of-uk-traditional-climbing-grades?s=2

Hale, A. and Anderson, I. (forthcoming) (Un)loved and (un)wanted: unsettling organisational methodologies through archaeological photography of graffiti at Pollphail and Scalan, Scotland in Hicks, D. and McFadyen, L. eds. (forthcoming) Archaeology and Photography: Time, Objectivity and Archive, Bloomsbury Photography Series.

Harrison, R; (2011) 'Counter-mapping' heritage, communities and places in Australia and the UK. In: Schofield, J and Szymanski, R, (eds.) Local Heritage, Global Context: Cultural Perspectives on Sense of Place, pp. 79-98. Ashgate, Farnham and Burlington

Hill, J, Moore, K. \& Wood, J (2012) Sport, History, and Heritage: Studies in Public Representation. The Boydell Press, Woodbridge.

Historic Environment Scotland (2015) Statement of Significance Dumbarton Castle, Appendix 1.

Historic Environment Scotland (2016(i)) https://canmore.org.uk/site/43376/dumbarton-castle (date accessed: 14.11. 16).

Historic Environment Scotland (2016(ii)) https://canmore.org.uk/site/350799/river-clydedumbarton-rock (date accessed: 14.11. 16)

Hunter, J (2011) Skye: The Island. Random House, London

Ingold, T. (2000) The Perception of the Environment. London: Routledge

Jeffrey, S. (2015) Challenging Heritage Visualisation: Beauty, Aura and Democratisation, in Open Archaeology 2015; 1 pp. 144-152.

Jeffrey, S, Hale, A, Jones, C, Jones, S \& Maxwell, M (2015), The ACCORD project:

Archaeological Community Co-Production of Research Resources in F Giligny , F Djindjian, L Costa, P Moscati \& S Robert (eds), CAA2014 21st century archaeology concepts, methods and tools: Proceedings of the 42nd Annual Conference on Computer Applications and Quantitative Methods in Archaeology, CAA 2014. CAA, Paris, pp. 289-295. 
Jeffrey, S., S. Jones, M. Maxwell, A. Hale and C. Jones, (forthcoming) 3D visualization, community collaboration and the production of (in)significance: the ACCORD Project. To be submitted to International Journal of Heritage Studies as part of a special edition on '(In)significance: values and valuing in heritage', edited by T. Ireland, S. Brown and J. Schofield.

Jones, S. 2016. Wrestling with the social value of heritage: problems, dilemmas and opportunities. Journal of Community Archaeology and Heritage, Vol 4(1), Online First, DOI:10.1080/20518196.2016.1193996

Jones, S., S. Jeffrey, M. Maxwell, A. Hale and C. Jones, (forthcoming) 3D heritage visualisation and the negotiation of authenticity: the ACCORD project.

Lloyd-Jones, R (2013). The Sunlit Summit, The Life of W.H. Murray. 1st Ed. Great Britain: Sandstone Press Ltd.

Lorimer, H. (2005) Cultural geography: the busyness of being 'more-than-representational', Progress in Human Geography Vol.29 (1): pp. 83-94

McCarthy, John. (2014) Multi-image photogrammetry as a practical tool for cultural heritage survey and community engagement. Journal of Archaeological Science 43: 175-185.

DOI:10.1016/j.jas.2014.01.010

Maxwell, M. (forthcoming) Power is in the Process: The ACCORD project, Internet Archaeology, special issue on 'digital creativity'.

Merrill, S.O.C. (2015) Keeping it real? Subcultural graffiti, street art, heritage and authenticity, International Journal of Heritage Studies 21 (4), pp. 369-389.

Miles. J., Mavrogordato, M., Sinclair, I., Hinton, D. and Earl, G. (2014) The Use of Computed Tomography for the Study of Archaeological Coins. In Archaeology in the Digital Era. Papers from the 40th Annual Conference of Computer Applications and Quantitative Methods in Archaeology (CAA'12). E-Proceedings. Southampton, UK, 26-30 March 2012. Edited by G. Earl, T. Sly, A. Chrysanthi, P. Murrieta-Flores, C. Papadopoulos, I. Romanowska, \& D. Wheatley. Amsterdam: Amsterdam University Press.

Reilly, P. and Beale, G. (2015) Additive archaeology: The spirit of virtual archaeology reprinted. In, Archaeological Research in the Digital Age. Proceedings of the 1st Computer Applications and Quantitative Methods in Archaeology Conference, Greek chapter (CAA GR 2014). 1st Computer Applications and Quantitative Methods in Archaeology Conference, Institute for Mediterranean Studies - Foundation of Research and Technology (IMS-Forth), $120-128$

Ryan, M. (2006) Dave MacLeod, The Modern traditionalist - E11, https://www.ukclimbing.com/articles/page.php?id=198 (date accessed: 22/01/17)

Schofield, J. (2012) The archaeology of sport and pastimes, World Archaeology, 44:2, DOI: 10.1080/00438243.2012.669603

Scottish Mountaineering Club (1994) Lowland Outcrops, Scottish Mountaineering Trust. 
Smith, L. (2006) The Uses of Heritage. London: Routledge

Smith, L and Waterton, E. (2009) Heritage, Communities and Archaeology, Duckworth, London.

Vertical Archaeology (2016) http://verticalarchaeology.com (date accessed: 05/10/16).

Williams, H. (2012) Dumbarton Rock graffiti clean-up concern raised by climbers. BBC Scotland News, http://www.bbc.co.uk/news/uk-scotland-glasgow-west-18841808 (date accessed: 02/04/17)

Wood, J. (2005) Talking Sport or Talking Balls? Realising the Value of Sports Heritage, Industrial Archaeology Review, 27:1, 137-144, DOI: 10.1179/030907205X44420.

Wood, J. (2016): Archaeology and Sports History: Towards an Inclusive Methodology, The International Journal of the History of Sport, DOI: 10.1080/09523367.2015.1124862.

Wylie, J. (2007) Landscape, Routledge: London.

\section{Figure captions}

Figure 1. A 1925 photograph of the north-west side of Dumbarton Rock, which captures the climbing landscape of vertiginous crags to the right of the castle buildings and the boulder field below. Crown Copyright: HES (SC1126854).

Figure 2. Some of the ACCORD team at Dumbarton Rock using the RTI recording technique to capture micro-details of the surface of a boulder. Crown Copyright: HES (DP234515).

Figure 3. Screen grab from Twitter of on-site data processing. Copyright: Alex Hale.

Figure 4. Chris Everett on the Pongo Boulder, tackling the In Bloom problem across the graffiti poem and later layers. Copyright: Stone Country.jpg.

Figure 5. Map of the boulders and associated graffiti at Dumbarton Rock. Copyright: John Stewart Watson. 